\title{
Polymorphism + I 7 C/G in Matrix Metalloprotease MMP8 decreases lung cancer risk
}

\author{
Patricia González-Arriaga ${ }^{1}$, M Felicitas López-Cima¹, Ana Fernández- \\ Somoano1, Teresa Pascual ${ }^{2}$, Manuel G Marrón ${ }^{2}$, Xose S Puente ${ }^{3}$ and \\ Adonina Tardón*1
}

Address: ${ }^{1}$ Departamento de Medicina, Unidad de Epidemiología Molecular del Instituto Universitario de Oncología, Universidad de Oviedo, 33006 Oviedo, Spain and CIBER Epidemiología y Salud Pública (CIBERESP), Spain, ²Servicio de Neumología, Hospital de Cabueñes, Gijón, Spain and ${ }^{3}$ Departamento de Bioquímica y Biología Molecular, Instituto Universitario de Oncología del Principado de Asturias, Universidad de Oviedo, 33006 Oviedo, Spain

Email: Patricia González-Arriaga - laboepic.uo@uniovi.es; M Felicitas López-Cima - laboepic.uo@uniovi.es; Ana FernándezSomoano - capua.uo@uniovi.es; Teresa Pascual - tpascualp@yahoo.es; Manuel G Marrón - mgamarron.granda@yahoo.es; Xose S Puente - xspuente@uniovi.es; Adonina Tardón* - atardon@uniovi.es

* Corresponding author

Published: 19 December 2008

BMC Cancer 2008, 8:378 doi:10.1 |86/|47|-2407-8-378
Received: 20 June 2008

Accepted: 19 December 2008

This article is available from: http://www.biomedcentral.com/147I-2407/8/378

(C) 2008 González-Arriaga et al; licensee BioMed Central Ltd.

This is an Open Access article distributed under the terms of the Creative Commons Attribution License (http://creativecommons.org/licenses/by/2.0), which permits unrestricted use, distribution, and reproduction in any medium, provided the original work is properly cited.

\begin{abstract}
Background: Matrix metalloproteases (MMPs) constitute a family of enzymes capable of degrading different components of the extracellular matrix and are implicated in the invasion of tumor cells through the basement membrane. Polymorphisms in MMP genes may result in changes in the expression of MMPs being associated with the development and progression of cancer. We have investigated the association between three polymorphisms $(-1607$ IG/2G, +17 C/G and -77 $\mathrm{A} / \mathrm{G}$ ) in the human collagenases MMPI, MMP8 and MMPI3 and the risk of development or progression of lung cancer.
\end{abstract}

Methods: A hospital-based case-control study was designed including $50 \mathrm{I}$ lung cancer patients and 510 controls matched. Genotypes were determined by PCR-RFLP. Results were analyzed using unconditional logistic regression, Cox's proportional hazard regression, and the Kaplan-Meier method.

Results: The MMPI and MMPI 3 promoter polymorphisms were not associated with lung cancer risk, while the $C / G$ polymorphism in MMP8 was associated with a statistically significant decreased risk of developing lung cancer (ORadj $=0.65 ; 95 \% \mathrm{Cl}=0.45-0.93$ ). The Kaplan-Meier analysis showed that the polymorphisms in MMPI, MMP8 and MMPI3 not seem to modify the overall survival. Multivariate analysis revealed that MMPI, MMP8 and MMPI3 polymorphisms are not independent prognostic factors for overall survival.

Conclusion: This study suggests that the polymorphism in MMP8 is associated with a decreased lung cancer risk, which can be used as a prognostic marker in lung cancer. 


\section{Background}

Lung cancer constitutes one of the leading causes of death in industrialized countries, and its incidence is rapidly growing in developing nations worldwide. Although tobacco smoke and other environmental pollutants are responsible for more than $80-90 \%$ of the cases in men [1], it is well established that less than 10-15\% of smokers develop lung cancer, indicating that other factors might contribute to the development of this disease [2,3]. In this regard, the availability of the human genome sequence has revealed the existence of numerous polymorphisms that affect both coding and non-coding regions [4], which might contribute to differences in the individual susceptibility to develop cancer [5-7].

One of the main characteristics of cancer cells is their ability to proliferate, invade the surrounding tissues and migrate to distant organs and form metastasis, thereby resulting in the emergence of disseminated metastases, which remains the primary cause of mortality in cancer patients [8-10]. Matrix metalloproteases (MMPs) constitute a group with the ability to cleave most components of the extracellular matrix, including collagen, laminin, fibronectin, proteoglycans or elastin, among others $[11,12]$. The expression of these MMPs by tumor cells might contribute to increasing the invasive potential of tumoral cells by allowing the remodeling of the extracellular matrix. In this sense, overexpression of collagenase1 (MMP1) and collagenase-3 (MMP13) has been associated with more aggressive tumors and poor prognosis in different tumor types [13,14]. Furthermore, MMP1 expression has been found to be an important marker of metastasis in breast cancer cells, confirming the importance of MMPs in tumor growth and invasion [13,15].

Polymorphisms in the regulatory regions of MMPs have been associated with changes in the expression level of these genes in different human diseases [16-18]. In fact, the $-16071 \mathrm{G} / 2 \mathrm{G}$ polymorphism in the promoter region of MMP1 creates an Ets binding site which increases the promoter activity of this gene [19]. Thus, the 2G allele of MMP1 has significantly higher transcriptional activity than the 1G allele and has been associated with an increased risk of common cancers, including oral, colorectal, renal and head and neck [17,20-22]. Furthermore, in colorectal and ovarian cancer, the presence of the $2 \mathrm{G}$ allele in the MMP1 gene was significantly associated with poorer survival of patients with cancer $[23,24]$. On the other hand, the $-77 \mathrm{~A} / \mathrm{G}$ polymorphism in the promoter region of MMP13, which modifies a PEA3 binding site resulting in reduced transcriptional activity of this gene [25], might contribute to reduce the risk of developing cancer. However, most of the epidemiological studies do not support this biological evidence. Two recent studies have shown no association between the $-77 \mathrm{~A} / \mathrm{G}$ polymor- phism and the risk of developing breast and nasopharyngeal cancer [26-28]. Finally, although recent studies in animal models have shown that mutant mice deficient in MMP8 are more susceptible to develop skin cancer, suggesting that MMP8 has a protective function against tumor developments [29,30], there are no epidemiological studies to analyze the association between polymorphisms in the promoter region of MMP8 and the susceptibility to develop cancer.

In this study, we reasoned that polymorphisms in the regulatory regions of the three human collagenases (MMP1, MMP8 and MMP13), affecting the expression level of these genes, might influence the risk and survival of lung cancer patients.

\section{Methods \\ Study subjects}

The detailed methods of recruiting participants for this hospital-based case-control study have been described elsewhere [31-33]. Briefly, a total of 501 incident cases of histologically confirmed lung cancer were recruited in two main hospitals of Asturias in Northern Spain [Cabueñes Hospital in Gijón (54\%) and San Agustín Hospital in Avilés (46\%)], following an identical protocol from October 2000 to April 2006. 510 controls were selected from patients admitted to participating hospitals for diagnoses believed to be unrelated to the exposures of interest, individually matched to the cases in ethnicity, gender and age ( \pm 5 years). The main specific pathologies of the final controls selected were: $41.1 \%$ inguinal and abdominal hernias (ICD-9: 550-553), 32.5\% injuries (ICD-9: 800-848, 860-869, 880-897), 8.8\% appendicitis (ICD-9: 540), and $13.3 \%$ intestinal obstructions (ICD-9: 560, 569, 574). The study was approved by the ethical committee of the hospitals, and written consent was obtained from each participant.

\section{Data collection}

Information on known or potential risk factors for lung cancer was collected personally through computerassisted questionnaires by trained interviewers during the first hospital admission for diagnosis. Structured questionnaires collected information on age, gender, sociodemographic characteristics, recent and prior tobacco use, and personal and family history of cancer (first-degree relatives) from each participant. A total of $93.8 \%$ eligible cases and $98.5 \%$ of eligible controls agreed to participate in the study and were interviewed. Reasons for eligibility are: pathology confirmation, residence, reassignments, and mental handicap. Of the 759 cases and 593 controls interviewed, 741 (97.6\%) cases and 556 (93.8\%) controls provided a blood or buccal cell sample for DNA extraction. Fifty-five individuals were excluded, seventeen individuals ( 5 cases and 12 controls) because of low amounts 
of DNA and thirty-eight ( 15 cases and 23 controls) by difficulties in the genotyping. Thirty seven individuals (26 cases and 11 controls) with missing information in the questionnaires and 194 cases without matched controls were also excluded from these analyses. Thus, the final study population available for this study was 501 cases and 510 controls, all of whom were Caucasian.

\section{Genotype determination}

The polymorphisms in the promoters of MMP genes analyzed in this study are shown in Table 1 . The polymerase chain reaction (PCR) combined with restriction fragment length polymorphism (RFLP) was used to determine the MMPs genotypes. Genomic DNA used for the assay was extracted from peripheral blood samples ( $96.5 \%$ of total) or exfoliated buccal cells (3.5\% of total) as previously described [34]. For quality control, genotyping was repeated randomly in at least $5 \%$ of the samples, and two of the authors independently reviewed all results. A quality control of 50 blood and mouthwash samples from the same participants ensured the reliability of genotyping results of mouthwash samples. In both quality controls no differences were found. PCR reactions were carried out in a total volume $10 \mu \mathrm{l}$ containing $20 \mathrm{ng}$ of genomic DNA, $0.25 \mathrm{mM}$ each dNTPs (Ecogen, Biologia Molecular S.L.), 0.2 units Taq polymerase (Biotools, Inc.) and $2.5 \mathrm{pmol}$ of each primer in $1 \times$ PCR buffer (Sigma-Aldrich Co.). The details of primers and PCR conditions used for the amplification of MMPs are shown in Table 1. For MMP1, the reverse primer was designed to introduce a recognition site for the restriction enzyme AluI (New England Biolabs, Inc.) by replacing a T with a $\mathrm{G}$. A $5 \mu \mathrm{l}$ aliquot of PCR products was digested overnight at $37^{\circ} \mathrm{C}$ with 0.4 units of the indicated restriction enzyme. After overnight digestion, the products were separated on agarose gels and stained with ethidium bromide (restriction enzyme are shown in Table 1). To verify that the data obtained by RFLP was coincident with the allele sequence, representative fragments were sequenced (data not shown).

\section{Statistical Analysis}

Tests for Hardy-Weinberg equilibrium among controls were conducted using observed genotype frequencies and a $\chi^{2}$ test with one degree of freedom. Univariate analysis was first performed to compare the distribution of age and gender and the frequencies of alleles and genotypes. The differences in the distribution between cases and controls were tested using the $\chi^{2}$, Fisher exact, and Mann-Whitney U-test, where appropriate. The crude odd ratios (ORs) were calculated by Wolf's method [35]. Multivariate unconditional logistic regression analysis with adjustment for age, gender, family history of cancer (first-degree relatives), and pack-years was performed to calculate adjusted ORs and 95\% confidence intervals (CIs). The survival curves were constructed using the Kaplan-Meier method, and differences between the groups were tested by the log-rank method. The multivariate analysis of probable prognostic factors for survival was performed using Cox's proportional hazard regression analysis and relative risk with 95\% confidence intervals, with adjustment for variables with statistical significance in univariate analysis. All statistical analyses were performed with STATA version 8 software. The sample size of our study for an allele frequency of $13 \%$ is enough to detect ORs greater than 0.65 with $84.5 \%$ power assuming a log-additive model, while for an allele frequency of $28 \%$ the power to detect an OR of 1.24 is $60 \%$. However, the power to detect an OR greater than 1.00 for $51 \%$ allele frequencies is only $5 \%$.

\section{Results \\ Population Characteristics}

The analysis included 501 lung cancer cases and 510 controls from the Caucasian population of Asturias, Northern Spain. The distributions of age, gender, smoking status, family history of cancer, histological types and clinical stages data for the cases among the study subjects are summarized in Table 2 . There were no statistically significant differences among cases and controls in terms of mean age and gender distributions, suggesting that the frequency matching was adequate. Furthermore, the control population was consistent with Hardy-Weinberg equilibrium for all polymorphisms studied.

We have determined the frequency of 3 polymorphisms in 3 human collagenases implicated in the degradation of the extracellular matrix components and basement membranes in lung cancer patients and matching controls in order to evaluate their association with the risk and the survival of lung cancer.

Table I: Details of PCR conditions and RFLPs studied

\begin{tabular}{|c|c|c|c|c|}
\hline Gene & Polymorphism & Primer sequence & PCR Conditions & Enzyme \\
\hline MMPI & $-|607| G / 2 G$ & $\begin{array}{l}\text { (F) TGA CTT TTA AAA CAT AGT CTA TGT TCA } \\
\text { (R) TCT TGG ATT GAT TTG AGA TAA GTC ATA gC }\end{array}$ & 35 cycles: $94^{\circ} \mathrm{C} 30 \mathrm{~s}, 54^{\circ} \mathrm{C} 30 \mathrm{~s}, 72^{\circ} \mathrm{C} 30 \mathrm{~s}$ & Alul \\
\hline MMP8 & $+17 C / G$ & $\begin{array}{l}\text { (F) CTG TTG AAG GCC TAG AGC TGC TGC TCC } \\
\text { (R) CAT CTT CTC TTC AAA CTC TAC CC }\end{array}$ & 30 cycles: $94^{\circ} \mathrm{C} 45 \mathrm{~s}, 64^{\circ} \mathrm{C} 45 \mathrm{~s}, 72^{\circ} \mathrm{C} \mathrm{I} \min$ & Ddel \\
\hline MMPI3 & $-77 \mathrm{~A} / \mathrm{G}$ & $\begin{array}{l}\text { (F) GAT ACG TTC TTA CAG AAG GGC } \\
\text { (R) GAC AAA TCA TCT TCA TCA CC }\end{array}$ & 30 cycles: $94^{\circ} \mathrm{C} 30 \mathrm{~s}, 54^{\circ} \mathrm{C} 30 \mathrm{~s}, 72^{\circ} \mathrm{C} 30 \mathrm{~s}$ & Brsl \\
\hline
\end{tabular}


Table 2: Characteristics of lung cancer cases and control patients in a Spanish population

\begin{tabular}{|c|c|c|c|}
\hline Variable & $\begin{array}{c}\text { Cases }(n=501) \\
n(\%)\end{array}$ & $\begin{array}{c}\text { Controls }(n=510) \\
n(\%)\end{array}$ & $\mathbf{P a}$ \\
\hline \multicolumn{4}{|l|}{ Gender } \\
\hline Male & $44 \mid(88.0)$ & $440(86.3)$ & \\
\hline Female & $60(12.0)$ & $70(13.7)$ & 0.406 \\
\hline Age (yrs), mean (SD) & $64.7(11.0)$ & $63.6(11.2)$ & 0.137 \\
\hline \multicolumn{4}{|l|}{ Smoking Status } \\
\hline Never & $35(7.0)$ & $136(26.7)$ & \\
\hline Ever & $466(93.0)$ & $374(73.3)$ & $<0.001$ \\
\hline Former & $211(45.9)$ & $215(59.9)$ & \\
\hline Current & $249(54.1)$ & $144(40.1)$ & $<0.001$ \\
\hline Pack-years b, mean (SD) & $63.0(36.5)$ & $39.4(33.3)$ & $<0.001$ \\
\hline \multicolumn{4}{|l|}{ Family history of cancer } \\
\hline No & $262(54.5)$ & $304(60.7)$ & \\
\hline Yes & $219(45.5)$ & $197(39.3)$ & 0.049 \\
\hline Lung cancer & $57(12.3)$ & $35(7.2)$ & \\
\hline Other cancers & $144(31.1)$ & $147(30.5)$ & 0.020 \\
\hline \multicolumn{4}{|l|}{ Histological types } \\
\hline Squamous cell carcinoma & $202(40.3)$ & & \\
\hline Adenocarcinoma & $143(28.5)$ & & \\
\hline Small cell carcinoma & $81(16.2)$ & & \\
\hline Non-differentiated & $37(7.4)$ & & \\
\hline Large cell carcinoma & $15(3.0)$ & & \\
\hline Others & $8(1.6)$ & & \\
\hline Clinical diagnosis & $2(0.4)$ & & \\
\hline Missing & $13(2.6)$ & & \\
\hline \multicolumn{4}{|l|}{ Clinical stages } \\
\hline 1 & $126(25.1)$ & & \\
\hline II & $28(5.6)$ & & \\
\hline III & $119(23.8)$ & & \\
\hline IV & $138(27.5)$ & & \\
\hline LS (Limited stage) & $39(7.8)$ & & \\
\hline EE (Extend stage) & $32(6.4)$ & & \\
\hline Missing & $19(3.8)$ & & \\
\hline
\end{tabular}

a Two-sided $\chi^{2}$ test and Mann-Whitney where appropriate

b Pack-years for ever smokers

\section{Analysis of the -I607 IG/2G polymorphism in the MMPI gene}

The distribution of MMP1 genotypes was very similar between cases and controls, with frequencies of $1 \mathrm{G} / 1 \mathrm{G}$, $1 \mathrm{G} / 2 \mathrm{G}$ and $2 \mathrm{G} / 2 \mathrm{G}$ genotypes of $25.5 \%, 49.5 \%$ and $25.0 \%$ in cases and $23.3 \%, 50.8 \%$ and $25.9 \%$ in controls, respectively. When we evaluated the association between MMP1 genotypes and lung cancer risk (Table 3), we found that individual with 2G/2G genotype and individual with 1G/ $2 \mathrm{G}$ or $2 \mathrm{G} / 2 \mathrm{G}$ genotype (2G carriers) presented a lack of association with lung cancer risk (adjusted $\mathrm{OR}=1.04$; $95 \% \mathrm{CI}=0.68-1.58$ and adjusted $\mathrm{OR}=0.99 ; 95 \% \mathrm{CI}=$ $0.71-1.40$, respectively). When we carried out stratified analysis by selected variables [see Additional file 1], no association was found between the MMP1 polymorphism and lung cancer risk for age, gender, smoking status, and family history of cancer. However, stratified analysis by histological types, showed that the MMP1 2G/2G genotype potentially tends to increase the risk of developing small cell lung cancer (adjusted OR $=2.06 ; 95 \% \mathrm{CI}=$ 0.94-4.51; $P=0.072$ ) [see Additional file 2].

Analysis of the -77 A/G polymorphism in the MMPI3 gene The frequency of the MMP13 -77G allele for cases and controls was 0.297 and 0.279 respectively, similar to the variant allele for MMP1. Similar to the $1 \mathrm{G} / 2 \mathrm{G}$ polymorphism in the MMP1 promoter, the MMP13 G/G genotype presented a lack of association with lung cancer risk 
Table 3: Analysis of polymorphisms and lung cancer risk estimates

\begin{tabular}{|c|c|c|c|c|c|c|}
\hline MMPs & Genotype & $\begin{array}{l}\text { Cases } \\
\text { n(\%) }\end{array}$ & $\begin{array}{c}\text { Controls } \\
\text { n(\%) }\end{array}$ & $\begin{array}{c}\text { Adjusted }^{\text {a OR }} \\
{[95 \% \mathrm{CI}]}\end{array}$ & $\mathbf{P}$ & $P$ trend \\
\hline \multirow[t]{4}{*}{ MMPI } & $I G / I G$ & $128(25.5)$ & $119(23.3)$ & Reference & & \\
\hline & $1 \mathrm{G} / 2 \mathrm{G}$ & 248 (49.5) & $259(50.8)$ & $0.97[0.68-1.40]$ & 0.884 & \\
\hline & $2 \mathrm{G} / 2 \mathrm{G}$ & $125(25.0)$ & $132(25.9)$ & $1.04[0.68-1.58]$ & 0.859 & 0.857 \\
\hline & $1 G / 2 G+2 G / 2 G$ & $373(74.5)$ & 391 (76.7) & $0.99[0.7 \mathrm{I}-1.40]$ & 0.975 & 0.975 \\
\hline \multirow[t]{2}{*}{ MMP8 } & $\mathrm{C} / \mathrm{C}$ & 392 (79.7) & $358(75.2)$ & Reference & & \\
\hline & $C / G+G / G$ & $100(20.3)$ & I 18 (24.8) & $0.65[0.45-0.93]$ & 0.019 & 0.019 \\
\hline \multirow[t]{4}{*}{ MMPI3 } & $\mathrm{A} / \mathrm{A}$ & $248(49.5)$ & $267(52.4)$ & Reference & & \\
\hline & $\mathrm{A} / \mathrm{G}$ & $208(4 I .5)$ & $197(39.4)$ & $1.24[0.91-1.69]$ & 0.174 & \\
\hline & $\mathrm{G} / \mathrm{G}$ & $45(9.0)$ & $42(8.2)$ & $1.23[0.72-2.11]$ & 0.452 & 0.200 \\
\hline & $A / G+G / G$ & $253(50.5)$ & $239(47.6)$ & $1.24[0.92-1.66]$ & 0.155 & 0.155 \\
\hline
\end{tabular}

aAdjusted by age, gender, tobacco consumption (in pack-years: never, $\leq 31.5$ and $>31.5$ ), and family history of cancer

(adjusted OR $=1.23 ; 95 \% \mathrm{CI}=0.72-2.11$ ) $($ Table 3$)$. However, the stratified analysis [see Additional file 3] showed that the genotype A/G was significantly associated with an increased risk of developing lung cancer in former smokers (adjusted OR $=1.60 ; 95 \% \mathrm{CI}=1.05-2.45 ; P=$ $0.030)$. Looking at the histological types [see Additional file 2], the results showed a higher risk of developing small cell lung cancer for heterozygous and homozygous genotypes $($ adjusted OR $=1.94 ; 95 \% \mathrm{CI}=1.09-3.45 ; P=$ 0.024 and adjusted $\mathrm{OR}=2.38 ; 95 \% \mathrm{CI}=1.01-5.65 ; P=$ 0.048 , respectively).

Analysis of the + I7 C/G polymorphism in the MMP8 gene In the case of the $+17 \mathrm{C} / \mathrm{G}$ polymorphism in MMP8, we found that the frequency of the $+17 \mathrm{G}$ allele was 0.130 in our population control. Due to the low number of individuals homozygous for the G/G genotype ( 8 cases and 6 controls), we examined the association between the presence of the $\mathrm{G}$ allele and lung cancer risk (Table 3). Thus, variant allele carriers showed a statistically significant decreased risk for developing lung cancer (adjusted OR = $0.65 ; 95 \% \mathrm{CI}=0.45-0.93 ; P=0.019)$. In the stratified analysis we found a statistically significant decreased risk of lung cancer in male (adjusted OR $=0.63 ; 95 \% \mathrm{CI}=$ 0.43-0.93; $P=0.021$ ), ever smokers (adjusted OR = 0.69; $95 \% \mathrm{CI}=0.48-0.97 ; P=0.034)$, and individual with family history of lung cancer (adjusted OR $=0.14 ; 95 \% \mathrm{CI}=$ 0.03-0.64; $P=0.011$ ) [see Additional file 4]. Looking at histological types [see Additional file 2], we observed that the $G$ variant allele was significantly associated with a decreased risk for small cell carcinoma (adjusted OR = $0.43 ; 95 \% \mathrm{CI}=0.20-0.89 ; P=0.023)$ and squamous cell carcinoma (adjusted OR $=0.51 ; 95 \% \mathrm{CI}=0.31-0.84 ; P=$ 0.008).

\section{Survival Analysis}

We have furthermore evaluated the progression and survival of lung cancer patients. Survival questionnaires were collected for lung cancer patients who had been diagnosed at least 24 months earlier. Thus, a total of 376 eligible cases were selected until April of 2005. The overall survival rate was $22 \%$. We used the Kaplan-Meier survival analysis to examine the relationship between polymorphisms in the promoter of the MMP genes and survival time.

The Kaplan-Meier survival analysis in individual carriers of the 2G allele for MMP1 not show a poorer survival statistically significant (Figure 1). In addition, the multivariate analysis was used to delineate significant prognostic factors for survival. This analysis showed that the MMP1 $2 \mathrm{G}$ allele was not an independent prognostic factor for overall survival after adjustment for clinical stages and metastases (adjusted HR = 1.23; 95\% CI = 0.93-1.63; $P=$ 0.153 ) (Table 4) and individuals with the $2 \mathrm{G}$ allele does not show a higher relative risk of death than the individuals with the $1 \mathrm{G} / 1 \mathrm{G}$ genotype.

Table 4: Analysis of polymorphisms and lung cancer overall survival

\begin{tabular}{|c|c|c|c|}
\hline MMPs & Genotype & $\begin{array}{c}\text { Adjusted* HR } \\
{[95 \% \mathrm{CI}]}\end{array}$ & $\mathbf{P}$ \\
\hline \multirow[t]{4}{*}{ MMPI } & IG/IG & Reference & \\
\hline & $1 \mathrm{G} / 2 \mathrm{G}$ & $1.25[0.93-1.69]$ & 0.143 \\
\hline & $2 \mathrm{G} / 2 \mathrm{G}$ & $1.19[0.85-1.66]$ & 0.312 \\
\hline & $1 G+2 G$ & $1.23[0.93-1.63]$ & 0.153 \\
\hline \multirow[t]{2}{*}{ MMP8 } & $\mathrm{C} / \mathrm{C}$ & Reference & \\
\hline & $C / G+G / G$ & $0.94[0.68-1.28]$ & 0.675 \\
\hline \multirow[t]{4}{*}{ MMPI3 } & $\mathrm{A} / \mathrm{A}$ & Reference & \\
\hline & $\mathrm{A} / \mathrm{G}$ & 0.91 [0.68-1.22] & 0.543 \\
\hline & $\mathrm{G} / \mathrm{G}$ & $1.53[0.95-2.47]$ & 0.078 \\
\hline & $A / G+G / G$ & $0.97[0.76-1.23]$ & 0.803 \\
\hline
\end{tabular}

*Adjusted by clinical stages and metastases 


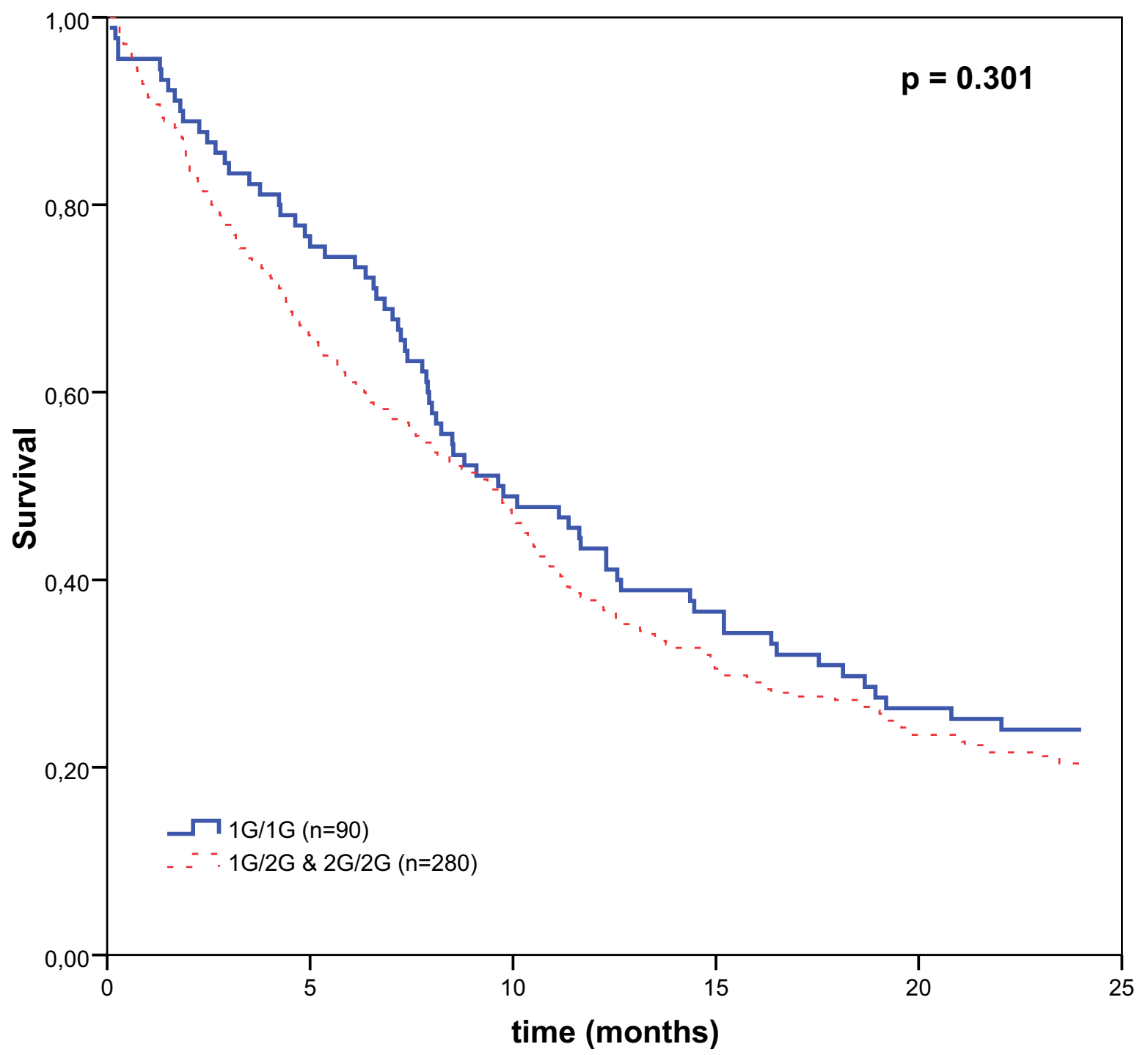

\section{Figure I}

Kaplan-Meier overall survival curves of patients with lung cancer by MMPI genotypes. The individual carriers of at least one $2 \mathrm{G}$ allele for MMPI do not show better survival than the individual with IG/IG homozygous genotype.

On the other hand, the analysis of the association between the $\mathrm{A} / \mathrm{G}$ polymorphism in the MMP13 promoter and survival time revealed that individual carriers of the $G$ allele for MMP13 showed no significant differences in survival time (Figure 2) and the multivariate analyses using Cox's proportional hazard regression analysis did not show statistically significant results (adjusted $\mathrm{HR}=0.97$; 95\% CI $=0.76-1.23)($ Table 4$)$.

Finally, although the G allele in MMP8 showed a protective effect against the development of lung cancer, it did not show a statistically significant protective effect associated with the survival time $(P=0.675)$. However, patients who are carriers of at least one $G$ allele not show a better overall survival than the individuals with the $\mathrm{C} / \mathrm{C}$ homozygous genotype, although a larger sample size would be necessary to confirm these differences (Figure 3 ). The multivariate analyses using Cox's proportional hazard regression analysis did not show statistically significant results (adjusted HR $=0.94 ; 95 \% \mathrm{CI}=0.68-1.28$ ) (Table 4). 


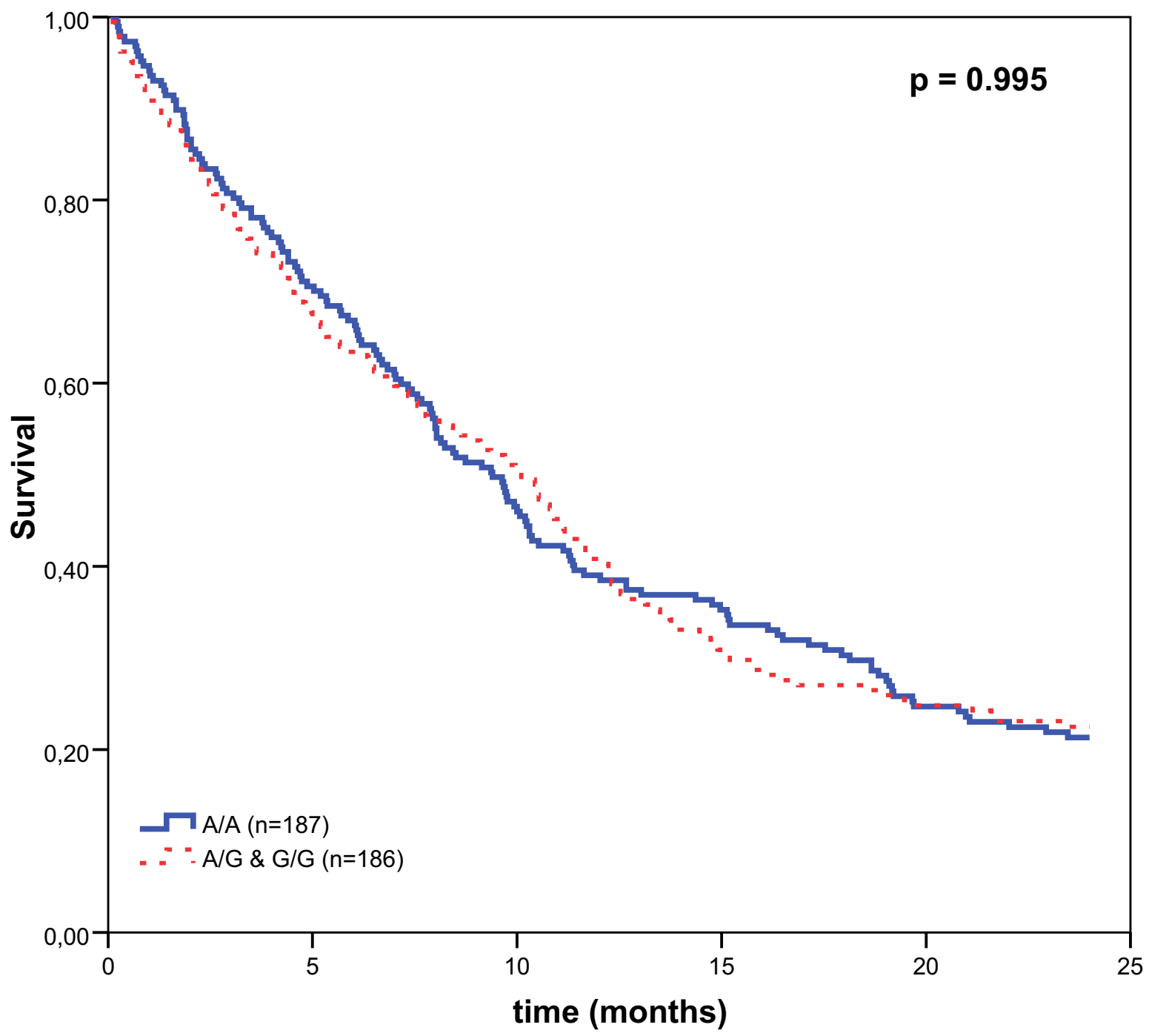

Figure 2

Kaplan-Meier overall survival curves of patients with lung cancer by MMPI 3 genotypes. The individual carriers of at least one $G$ allele for MMPI 3 do not show better survival than the individual with A/A homozygous genotype.

\section{Discussion}

In this study we have investigated the effect of polymorphisms in the promoter regions of the three human collagenases (MMP1, MMP8 and MMP13) and the individual risk of developing lung cancer in a group of 501 cases and 510 controls. We have evaluated whether these polymorphisms could influence the progression and survival of these lung cancer patients. Our results suggest that the studied polymorphism in the promoter region of the MMP8 gene is associated with lung cancer risk. Thus, individuals with at least one $G$ variant allele showed a protec- tive effect against developing lung cancer compared to the reference genotype, while this polymorphism not seems associated with a higher survival rate and a better prognosis. On the other hand, the studied polymorphisms in the MMP1 and MMP13 genes do not seem to influence the individual risk to develop lung cancer and survival time in our population.

Our study has several strengths, including high participation of eligible cases (rate 93.8\%) and quite large sample size from a homogeneous population of similar ancestry 


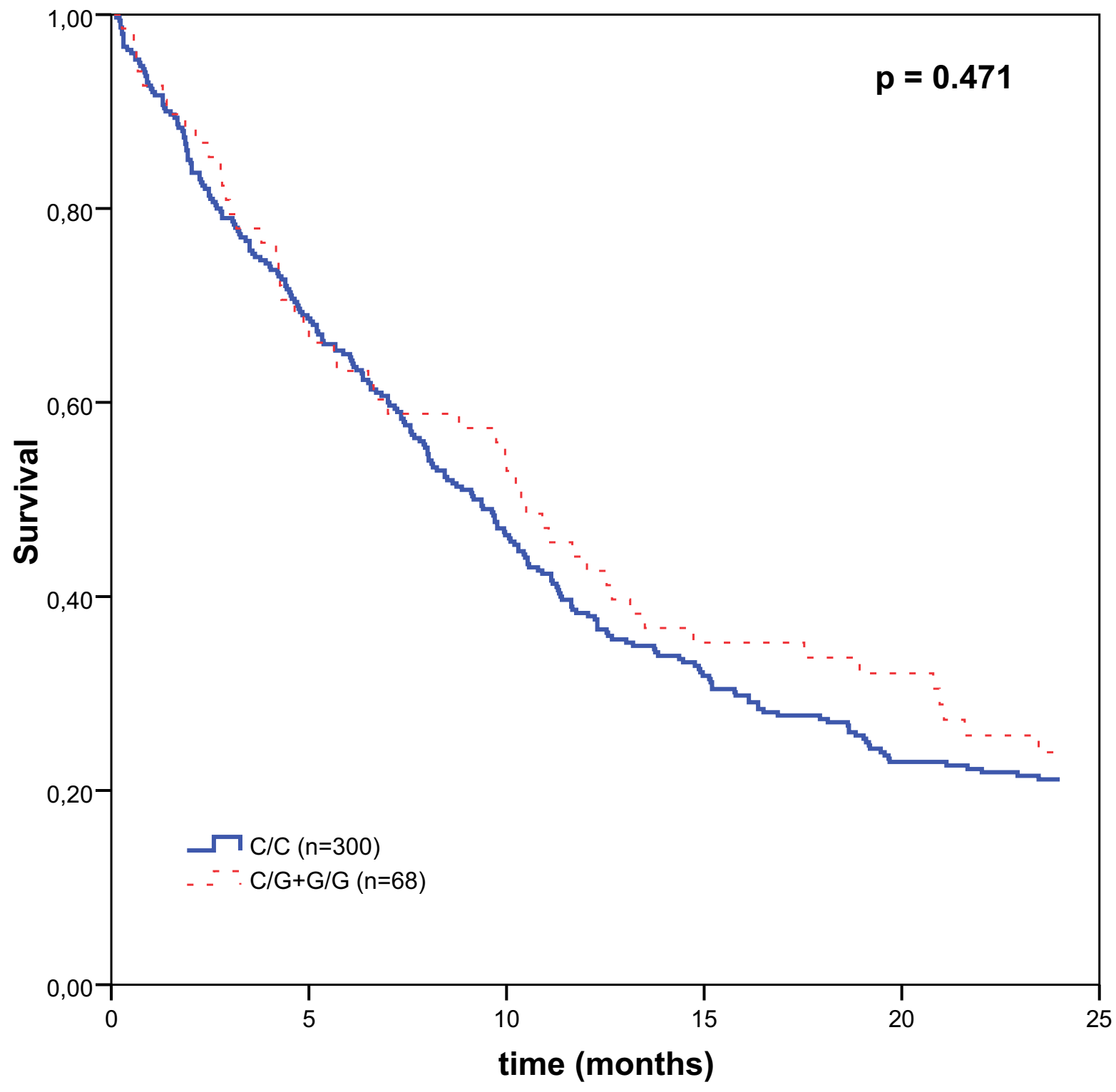

Figure 3

Kaplan-Meier overall survival curves of patients with lung cancer by MMP8 genotypes. The individual carriers of at least one $\mathrm{G}$ allele for MMP8 do not show better survival than the individual with $\mathrm{C} / \mathrm{C}$ homozygous genotype.

(501 cases and 510 controls). Likewise, all our cases were pathologically confirmed and finally we applied a severe quality control for genotyping. The main limitations of our study were hospital-based subjects, recall bias due to the fact that information on smoking exposure was obtained retrospectively, and especially possible false positive associations, due to the multiple comparisons made. We cannot exclude the possibility that some of these asso- ciations may represent chance finding, because the power to detect interactions was limited. To minimize selection bias, we carefully selected controls from patients admitted for various diagnoses that were thought to be unrelated to exposures of interest. Nevertheless, a recent paper from Campbell et al. [36] reported that European populations may display various levels of genetic substructure which may lead to false positive associations due to population 
stratification. In our study, we controlled for this possibility by matching individuals on the basis of European ancestry.

Several reports have showed that proteases from the MMP family are implicated in tumor invasion and metastasis due to their ability to degrade numerous components of the extracellular matrix and basement membrane [37-39]. Focusing on lung cancer, upregulation of certain MMPs, like MMP1 and MMP13, has been associated with the progression and poorer prognosis of squamous cell carcinoma and adenocarcinoma [40-43], suggesting that changes affecting the expression level of these genes could contribute to the progression of this disease. The polymorphisms analyzed in this study have been previously shown to modify the transcriptional activity of the corresponding MMPs [25,44,45].

The $2 \mathrm{G}$ allele of the $1 \mathrm{G} / 2 \mathrm{G}$ polymorphism in the MMP1 promoter creates an extra Ets-binding site, which results in increased transcriptional activity of this gene [44]. Thus, the presence of the MMP1 polymorphism has been associated with an increased risk of developing different human cancers including colorectal, renal and head and neck $[17,21,46]$. For lung cancer, the number of studies is still very limited. Recent studies carried out in Caucasian and Asian populations found an association between the $2 \mathrm{G}$ polymorphism in the MMP1 promoter and an increased risk of developing lung cancer $[47,48]$. However, and in agreement with our results, other reports studying the $1 \mathrm{G} / 2 \mathrm{G}$ polymorphism in larger populations have not found an increased risk for developing lung cancer for the $2 \mathrm{G}$ allele, although stratified analysis by various variables showed statistically significant associations $[28,49,50]$.

Although polymorphisms in MMP genes have been studied extensively with regard to risk of cancer, much less is known about survival outcomes. Studies in other cancers are provocative and suggest that some MMP polymorphisms may have a prognostic role. Accordingly, the 2G allele of the MMP1 $1 \mathrm{G} / 2 \mathrm{G}$ polymorphism has been associated with worse survival among patients with colorectal [24] and ovarian cancer [23]. However, a study in patients with stage I for NSCLC carrying the variant $2 \mathrm{G}$ allele not showed an association between this polymorphism and survival time [51]. Our results do not suggest an association between this polymorphism and decreased survival and this polymorphism is not an independent prognostic factor of overall survival.

On the other hand, the polymorphism -77 A/G in the promoter region of MMP13, which modifies a PEA3 binding site, results in a reduced transcriptional activity of this gene [25], which might contribute to reducing the risk of developing cancer. However, most of the epidemiological studies do not support this biological evidence. Two recent studies of different types of cancer have shown no association between the $-77 \mathrm{~A} / \mathrm{G}$ polymorphism and the risk of developing breast and nasopharyngeal cancer $[26,27]$. Our results constitute the first report that analyze this polymorphism in lung cancer and suggest that the -77 A/G polymorphism in MMP13 does not contribute to the susceptibility to develop lung cancer in the Asturian population. Thus, the MMP13 polymorphism does not seem to contribute to initial stages of tumor development, although this evidence needs to be confirmed in further studies. Furthermore, this polymorphism doesn't appear to have an effect on patient survival and the multivariate analyses using Cox's proportional hazard regression analysis did not show statistically significant results. These results don't support the biological evidence that MMP13 is implicated in tumor growth and dissemination. However, these findings need to be verified in larger clinical studies.

In the stratified analysis by histological types, we observed that homozygotes for variant allele of polymorphisms in MMP1 and MMP13 genes increase the risk of developing small cell carcinoma. Previous studies have shown that between $70-100 \%$ of small lung carcinomas express MMP13 and between 60-70\% express MMP1 [52], which suggests that metalloproteinases could be involved in the initial stages of developing this histological types, although the molecular mechanism by which they could participate in this process is still unknown.

Contrary to results observed for polymorphisms in MMP1 and MMP13, the polymorphism studied in MMP8 was associated with a reduced individual susceptibility to develop lung cancer in our study. MMP8 cleaves type I collagen very efficiently and is predominantly expressed and stored in polymorphonuclear (PMN) leukocytes. The physiological role of MMP8 is, however, still unknown. Recent studies in animal models have shown that mutant mice deficient in MMP8 are more susceptible to develop skin cancer, predicting that MMP8 has a protective function against tumor developments [29,30]. In addition, a direct anti-metastatic role for MMP8 was confirmed by Montel et al., who found that overexpression of MMP8 in breast cancer cell lines decreased metastases, which suggests that a greater expression of MMP8 could result in a lower incidence of cancer and a better prognosis [30]. Our data suggest that individual carriers of the allele $G$ in MMP8 had lower susceptibility to develop lung cancer, possibly due to the ability of collagenase- 2 to induce antimetastatic processes. However, these findings need to be verified in larger epidemiological and clinical studies. In 
the same way, to evaluate gene-gene and gene-environment interactions between the polymorphisms and lung cancer risk and survival time in our population, a single larger sample with thousands of subjects and tissue-specific biochemical and biological characterizations are required.

\section{Conclusion}

In conclusion, this work represents the first study in which polymorphisms in this important group of MMPs (MMP1, MMP8 and MMP13) are analyzed together to understand their contribution to lung cancer development and the effect on disease progression and survival in the Caucasian population. We attempt to contribute to the study of useful biomarkers for screening high-risk populations for primary prevention and early detection of lung cancer. In the same way, as polymorphisms in the promoter region mainly result in changes in expression, it would be interesting to conduct a study of gene expression to confirm our findings. Finally, the biological function of MMPs apparently is more complex than being only involved in growth or tumor progression [53], so further studies would be required to elucidate the molecular mechanisms implicated in these complex processes.

\section{Competing interests}

The authors declare that they have no competing interests.

\section{Authors' contributions}

PGA carried out molecular genetic studies and drafted the manuscript. MFLC participated in the molecular genetic studies and revised the manuscript. AFS performed the statistical analysis. TP and MGM participated in the patient enrollment. XSP participated in the design of the molecular genetic study and revised the manuscript. AT conceived of the study, participated in its design and coordination, and revised the manuscript. All authors read and approved the final manuscript.

\section{Additional material}

\section{Additional file 1}

Multivariate analysis of collagenase-1 (MMP1) stratified by selected variables. This table shows the stratified analysis by selected variables of MMP1 -1607 1G/2G polymorphism.

Click here for file

[http://www.biomedcentral.com/content/supplementary/14712407-8-378-S1.doc]

\section{Additional file 2}

Multivariate analysis of collagenases and lung cancer risk by histological types. This table shows the stratified analysis by histological types of MMP1, 13 and 8.

Click here for file

[http://www.biomedcentral.com/content/supplementary/14712407-8-378-S2.doc]

\section{Additional file 3}

Multivariate analysis of collagenase-3 (MMP13) stratified by selected variables. This table shows the stratified analysis by selected variables of MMP13 -77 A/G polymorphism.

Click here for file

[http://www.biomedcentral.com/content/supplementary/1471-

2407-8-378-S3.doc]

\section{Additional file 4}

Multivariate analysis of collagenase-2 (MMP8) stratified by selected variables. This table shows the stratified analysis by selected variables of MMP8 +17 C/G polymorphism.

Click here for file

[http://www.biomedcentral.com/content/supplementary/14712407-8-378-S4.doc]

\section{Acknowledgements}

We are in debt to the patients who participated in the study. We also thank the study monitors Cristina Arias, Avelino Menendez and Beatriz Lastra (Unidad de Epidemiología Molecular - IUOPA) for collecting information, and Alex Leader for proofreading the text. Finally, Instituto Universitario de Oncologia is supported by Obra Social Cajastur-Asturias, Spain.

\section{References}

I. Levi F: Cancer prevention: epidemiology and perspectives. Eur J Cancer 1999, 35( 1 4): 1912-1924.

2. Tardon A, Lee WJ, Delgado-Rodriguez M, Dosemeci M, Albanes D, Hoover R, Blair A: Leisure-time physical activity and lung cancer: a meta-analysis. Cancer Causes Control 2005, I 6(4):389-397.

3. Rodriguez V, Tardon A, Kogevinas M, Prieto CS, Cueto A, Garcia M, Menendez IA, Zaplana J: Lung cancer risk in iron and steel foundry workers: a nested case control study in Asturias, Spain. Am J Ind Med 2000, 38(6):644-650.

4. A haplotype map of the human genome. Nature 2005, 437(7063): I299-1320.

5. Zhou G, Zhai Y, Cui Y, Zhang X, Dong X, Yang H, He Y, Yao K, Zhang $\mathrm{H}$, Zhi L, et al:: MDM2 Promoter SNP309 Is Associated with Risk of Occurrence and Advanced Lymph Node Metastasis of Nasopharyngeal Carcinoma in Chinese Population. Clin Cancer Res 2007, 13(9):2627-2633.

6. Raptis S, Mrkonjic M, Green RC, Pethe VV, Monga N, Chan YM, Daftary D, Dicks E, Younghusband BH, Parfrey PS, et al.: MLH I -93G $>$ A promoter polymorphism and the risk of microsatelliteunstable colorectal cancer. I Natl Cancer Inst 2007, 99(6):463-474.

7. Ohmiya N, Taguchi A, Mabuchi N, Itoh A, Hirooka Y, Niwa Y, Goto $\mathrm{H}$ : MDM2 promoter polymorphism is associated with both an increased susceptibility to gastric carcinoma and poor prognosis. J Clin Oncol 2006, 24(27):4434-4440.

8. Fidler IJ: The pathogenesis of cancer metastasis: the 'seed and soil' hypothesis revisited. Nat Rev Cancer 2003, 3(6):453-458.

9. Hynes RO: Metastatic potential: generic predisposition of the primary tumor or rare, metastatic variants-or both? Cell 2003, I I 3(7):821-823.

10. Gupta GP, Massague J: Cancer metastasis: building a framework. Cell 2006, I27(4):679-695.

II. Visse R, Nagase H: Matrix metalloproteinases and tissue inhibitors of metalloproteinases: structure, function, and biochemistry. Circ Res 2003, 92(8):827-839.

12. Stamenkovic I: Extracellular matrix remodelling: the role of matrix metalloproteinases. J Pathol 2003, 200(4):448-464.

13. Gupta GP, Nguyen DX, Chiang AC, Bos PD, Kim JY, Nadal C, Gomis RR, Manova-Todorova K, Massague J: Mediators of vascular remodelling co-opted for sequential steps in lung metastasis. Nature 2007, 446(7137):765-770. 
14. Leeman MF, McKay JA, Murray GI: Matrix metalloproteinase I3 activity is associated with poor prognosis in colorectal cancer. J Clin Pathol 2002, 55( ( 0):758-762.

15. Overall CM, Lopez-Otin C: Strategies for MMP inhibition in cancer: innovations for the post-trial era. Nat Rev Cancer 2002, 2(9):657-672.

16. Zhou Y, Yu C, Miao X, Wang Y, Tan W, Sun T, Zhang X, Xiong P, Lin $D$ : Functional haplotypes in the promoter of matrix metalloproteinase-2 and lung cancer susceptibility. Carcinogenesis 2005, 26(6): || |7-|| $2 \mid$.

17. $\mathrm{P}$ Oc, Leksrisakul P, Sangruchi S: A functional polymorphism in the matrix metalloproteinase-I gene promoter is associated with susceptibility and aggressiveness of head and neck cancer. Int J Cancer 2006, I I 8( ( 0):2548-2553.

18. Kader AK, Liu J, Shao L, Dinney CP, Lin J, Wang Y, Gu J, Grossman $\mathrm{HB}, \mathrm{Wu} X$ : Matrix metalloproteinase polymorphisms are associated with bladder cancer invasiveness. Clin Cancer Res 2007, I3(9):26|4-2620.

19. Fujimoto T, Parry S, Urbanek M, Sammel M, Macones G, Kuivaniemi $\mathrm{H}$, Romero R, Strauss JF 3rd: A single nucleotide polymorphism in the matrix metalloproteinase-I (MMP-I) promoter influences amnion cell MMP-I expression and risk for preterm premature rupture of the fetal membranes. J Biol Chem 2002, 277(8):6296-6302.

20. Cao Z, Li C, Jin L, Corbet EF: Association of matrix metalloproteinase-I promoter polymorphism with generalized aggressive periodontitis in a Chinese population. I Periodontal Res 2005, 40(6):427-43।.

21. Hinoda Y, Okayama N, Takano N, Fujimura K, Suehiro Y, Hamanaka Y, Hazama S, Kitamura Y, Kamatani N, Oka M: Association of functional polymorphisms of matrix metalloproteinase (MMP)and MMP-3 genes with colorectal cancer. Int J Cancer 2002, 102(5):526-529.

22. Hirata $H$, Naito $K$, Yoshihiro $S$, Matsuyama $H$, Suehiro $Y$, Hinoda $Y$ : A single nucleotide polymorphism in the matrix metalloproteinase-I promoter is associated with conventional renal cell carcinoma. Int I Cancer 2003, I06(3):372-374.

23. Six L, Grimm C, Leodolter S, Tempfer C, Zeillinger R, Sliutz G, Speiser $P$, Reinthaller A, Hefler LA: A polymorphism in the matrix metalloproteinase-I gene promoter is associated with the prognosis of patients with ovarian cancer. Gynecol Oncol 2006, 100(3):506-510.

24. Zinzindohoue F, Lecomte T, Ferraz JM, Houllier AM, Cugnenc PH, Berger A, Blons $H$, Laurent-Puig P: Prognostic significance of MMP-I and MMP-3 functional promoter polymorphisms in colorectal cancer. Clin Cancer Res 2005, I I (2 Pt I):594-599.

25. Yoon S, Kuivaniemi H, Gatalica Z, Olson JM, Buttice G, Ye S, Norris BA, Malcom GT, Strong JP, Tromp G: MMPI3 promoter polymorphism is associated with atherosclerosis in the abdominal aorta of young black males. Matrix Biol 2002, 21 (6):487-498.

26. Lei H, Hemminki K, Altieri A, Johansson R, Enquist K, Hallmans G, Lenner $P$, Forsti A: Promoter polymorphisms in matrix metalloproteinases and their inhibitors: few associations with breast cancer susceptibility and progression. Breast Cancer Res Treat 2007, I 03(I):6I-69.

27. Zhou G, Zhai Y, Cui Y, Oiu W, Yang H, Zhang X, Dong X, He Y, Yao $\mathrm{K}$, Zhang $\mathrm{H}$, et al.: Functional polymorphisms and haplotypes in the promoter of the MMP2 gene are associated with risk of nasopharyngeal carcinoma. Hum Mutat 2007. 28(II): $109 \mid-1097$.

28. Fang S, Jin X, Wang R, Li Y, Guo W, Wang N, Wang Y, Wen D, Wei L, Zhang J: Polymorphisms in the MMPI and MMP3 promoter and non-small cell lung carcinoma in North China. Carcinogenesis 2005, 26(2):48I-486.

29. Balbin M, Fueyo A, Tester AM, Pendas AM, Pitiot AS, Astudillo A, Overall CM, Shapiro SD, Lopez-Otin C: Loss of collagenase-2 confers increased skin tumor susceptibility to male mice. Nat Genet 2003, 35(3):252-257.

30. Montel V, Kleeman J, Agarwal D, Spinella D, Kawai K, Tarin D: Altered metastatic behavior of human breast cancer cells after experimental manipulation of matrix metalloproteinase 8 gene expression. Cancer Res 2004, 64(5):1687-1694.

31. Marin MS, Lopez-Cima MF, Garcia-Castro L, Pascual T, Marron MG Tardon A: Poly (AT) polymorphism in intron II of the XPC DNA repair gene enhances the risk of lung cancer. Cancer Epidemiol Biomarkers Prev 2004, I3(I I Pt I): | 788-1793.
32. Lopez-Cima MF, Gonzalez-Arriaga P, Garcia-Castro L, Pascual T, Marron MG, Puente XS, Tardon A: Polymorphisms in XPC, $X P D, X R C C I$, and $X R C C 3$ DNA repair genes and lung cancer risk in a population of Northern Spain. BMC Cancer 2007 $7(1): 162$.

33. Fernandez-Rubio A, Lopez-Cima MF, Gonzalez-Arriaga P, GarciaCastro L, Pascual T, Marron MG, Tardon A: The TP53 Arg72Pro polymorphism and lung cancer risk in a population of Northern Spain. Lung Cancer 2008

34. Miller SA, Dykes DD, Polesky HF: A simple salting out procedure for extracting DNA from human nucleated cells. Nucleic Acids Res 1988, 16(3): 1215.

35. Wolf FM: Meta-analysis: quantitative methods for research synthesis. Sage Publications 1986

36. Campbell CD, Ogburn EL, Lunetta KL, Lyon HN, Freedman ML, Groop LC, Altshuler D, Ardlie KG, Hirschhorn JN: Demonstrating stratification in a European American population. Nat Genet 2005, 37(8):868-872

37. Egeblad M, Werb Z: New functions for the matrix metalloproteinases in cancer progression. Nat Rev Cancer 2002, 2(3): $16 \mid-174$

38. Jones JL, Walker RA: Control of matrix metalloproteinase activity in cancer. J Pathol 1997, 183(4):377-379.

39. Brinckerhoff CE, Rutter JL, Benbow U: Interstitial collagenases as markers of tumor progression. Clin Cancer Res 2000, 6( I 2):4823-4830

40. Lin TS, Chiou SH, Wang LS, Huang HH, Chiang SF, Shih AY, Chen YL, Chen CY, Hsu CP, Hsu NY, et al.: Expression spectra of matrix metalloproteinases in metastatic non-small cell lung cancer. Oncol Rep 2004, I 2(4):717-723.

4I. Bugdayci G, Kaplan T, Sezer S, Turhan T, Koca Y, Kocer B, Yildirim E: Matrix metalloproteinase-9 in broncho-alveolar lavage fluid of patients with non-small cell lung cancer. Exp Oncol 2006, 28(2): $|69-| 7 \mid$

42. Leinonen T, Pirinen R, Bohm J, Johansson R, Ropponen K, Kosma VM: Expression of matrix metalloproteinases 7 and 9 in nonsmall cell lung cancer. Relation to clinicopathological factors, beta-catenin and prognosis. Lung Cancer 2006, $5 I(3): 3|3-32|$.

43. Hsu CP, Shen GH, Ko JL: Matrix metalloproteinase- 13 expression is associated with bone marrow microinvolvement and prognosis in non-small cell lung cancer. Lung Cancer 2006, 52(3):349-357.

44. Rutter JL, Mitchell TI, Buttice G, Meyers J, Gusella JF, Ozelius LJ, Brinckerhoff CE: A single nucleotide polymorphism in the matrix metalloproteinase-I promoter creates an Ets binding site and augments transcription. Cancer Res 1998 58(23):532I-5325.

45. Wang H, Parry S, Macones G, Sammel MD, Ferrand PE, Kuivaniemi H, Tromp G, Halder I, Shriver MD, Romero R, et al.: Functionally significant SNP MMP8 promoter haplotypes and preterm premature rupture of membranes (PPROM). Hum Mol Genet 2004, I 3(2 I):2659-2669.

46. Hirata H, Okayama N, Naito K, Inoue R, Yoshihiro S, Matsuyama H, Suehiro $Y$, Hamanaka $Y$, Hinoda $Y$ : Association of a haplotype of matrix metalloproteinase (MMP)-I and MMP-3 polymorphisms with renal cell carcinoma. Carcinogenesis 2004, 25(I 2):2379-2384.

47. Zhu Y, Spitz MR, Lei L, Mills GB, Wu X: A single nucleotide polymorphism in the matrix metalloproteinase-I promoter enhances lung cancer susceptibility. Cancer Res 2001, 6I(2I):7825-7829.

48. Zhang WQ, Lin H, Zhou YA, Wang Y], Cheng QS: [Association of MMPI-I607(IG > 2G)single nucleotide polymorphism with susceptibility to lung cancer in Northwestern Chinese population of Han nationality]. Zhonghua Yi Xue Yi Chuan Xue Za Zhi 2006, 23(3):3|3-3|5.

49. Su L, Zhou W, Asomaning K, Lin X, Wain JC, Lynch TJ, Liu G, Christiani DC: Genotypes and haplotypes of matrix metalloproteinase $I, 3$ and 12 genes and the risk of lung cancer. Carcinogenesis 2006, 27(5): 1024-1029.

50. Su L, Zhou W, Park S, Wain JC, Lynch TJ, Liu G, Christiani DC Matrix metalloproteinase-I promoter polymorphism and lung cancer risk. Cancer Epidemiol Biomarkers Prev 2005, I4(3):567-570. 
5I. Heist RS, Marshall AL, Liu G, Zhou W, Su L, Neuberg D, Lynch TJ, Wain J, Christiani DC: Matrix metalloproteinase polymorphisms and survival in stage I non-small cell lung cancer. Clin Cancer Res 2006, I 2( I 8):5448-5453.

52. Michael M, Babic B, Khokha R, Tsao M, HoJ, Pintilie M, Leco K, Chamberlain D, Shepherd FA: Expression and prognostic significance of metalloproteinases and their tissue inhibitors in patients with small-cell lung cancer. J Clin Oncol 1999, I7(6): I 802-1808.

53. Lopez-Otin C, Matrisian LM: Emerging roles of proteases in tumour suppression. Nat Rev Cancer 2007, 7(10):800-808.

\section{Pre-publication history}

The pre-publication history for this paper can be accessed here:

http://www.biomedcentral.com/1471-2407/8/378/pre pub

Publish with Bio Med Central and every scientist can read your work free of charge

"BioMed Central will be the most significant development for disseminating the results of biomedical research in our lifetime."

Sir Paul Nurse, Cancer Research UK

Your research papers will be:

- available free of charge to the entire biomedical community

- peer reviewed and published immediately upon acceptance

- cited in PubMed and archived on PubMed Central

- yours - you keep the copyright

Submit your manuscript here:

http://www.biomedcentral.com/info/publishing_adv.asp
BioMedcentral 